Karadeniz Fen Bilimleri Dergisi

The Black Sea Journal of Sciences

ISSN (Online): 2564-7377

Araștırma Makalesi / Research Article

\title{
Bayes Ăgları-K2 Algoritması Üzerine Bir Çalışma
}

\author{
Esin KÖKSAL BABACAN*, Melike Özlem KARADUMAN \\ Ankara Üniversitesi, Fen Fakültesi, İstatistik Bölümü, Ankara, Türkiye
}

"Sorumlu Yazar: ekoksal@science.ankara.edu.tr

Geliş Tarihi: 26.04 .2018

Kabul Tarihi: 29.10 .2018

\section{Öz}

Değişkenler arasındaki ilişkilerin oklar ve düğümler yardımıyla grafiksel gösterimi Bayes ağlarının temelini oluşturur. Okların yönüne göre ebeveyn ve çocuk isimlerini alan rasgele değişkenler ile bu rasgele değişkenlere ait koşullu ve marjinal olasılıklar istenilen bir olayın olasılığının hesaplanmasında araştırmacıya büyük kolaylık sağlar. Bayes ağları "Nedensel Bayes Ağları" ve "Algoritmalara Dayalı Bayes Ağları" olmak üzere iki yöntemle oluşturulabilir. Her iki yöntemin kendi içerisinde avantajları mevcuttur ve araştırma konusuna göre farklılık göstermektedir. Ağ oluştururken kullanılan farklı bir çok algoritma vardır. $\mathrm{Bu}$ algoritmalardan biri $\mathrm{K} 2$ algoritmasıdır. Bu çalışmada birer örnek ile Nedensel Bayes Ağlarının ve Algoritmalara Dayalı Bayes Ağlarının nasıl oluşturulduğu anlatılmaktadır.

Anahtar kelimeler: Bayes ağları, K2 algoritması, Nedensel Bayes ağları, Algoritmalara dayalı Bayes ağları.

\section{A study on Bayesian Network-K2 Algorithm}

\begin{abstract}
The basis of the Bayesian networks is the graphical representation of the arrows and nodes which represent relationships between variables. Random variables that take parent and child names according to the direction of the arrows and conditional and marginal probabilities of these random variables provide great convenience to the researcher in calculating the likelihood of a desired event. Bayesian networks can be created in two ways: "Causal Bayesian Networks" and "Algorithm Based Bayesian Networks". Both methods have advantages within themselves and vary according to the research topic. There are many different algorithms that are used when networking. One of these algorithms is the $\mathrm{K} 2$ algorithm. In this work, it is explained how to construct Causal Bayesian Networks and Algorithm Based Bayesian Networks on one example for each.
\end{abstract}

Key words: Bayesian Networks, K2 algorithm, Causal Bayesian Networks, Algorithm Based Bayesian Networks. 


\section{Giriş}

Bayes Ağları değişkenlerin düğümler, değişkenler arası olasılıksal bağımlılık ilişkilerinin ise yönlü oklar aracılığıyla gösterildiği yönlü, çevrimsiz, olasılıksal ağlardır (Pearl,1988). Bayes Ağları, düğümler ve oklar aracılığıyla değişkenler arası olasılıksal ilişkilerin gösterildiği grafiksel kısım ile değişkenlere ait koşullu olasılık tabloları olmak üzere iki ana parçadan oluşur. Yorumlama ve çıkarsama açısından elverişli olması sebebiyle, biyoloji, fizik, kimya, psikoloji, tıp gibi birçok alanda kullanılmaktadır. Bayes ağlarının tanımı ilk kez Judea Pearl tarafından 1985 yılında yapılmıştır. Okun yönüne göre değişkenler ebeveyn ve çocuk isimlerini alırlar. Ebeveyn ve çocuk ilişkisi aşağıdaki gibi basit bir şema ile gösterilebilir:

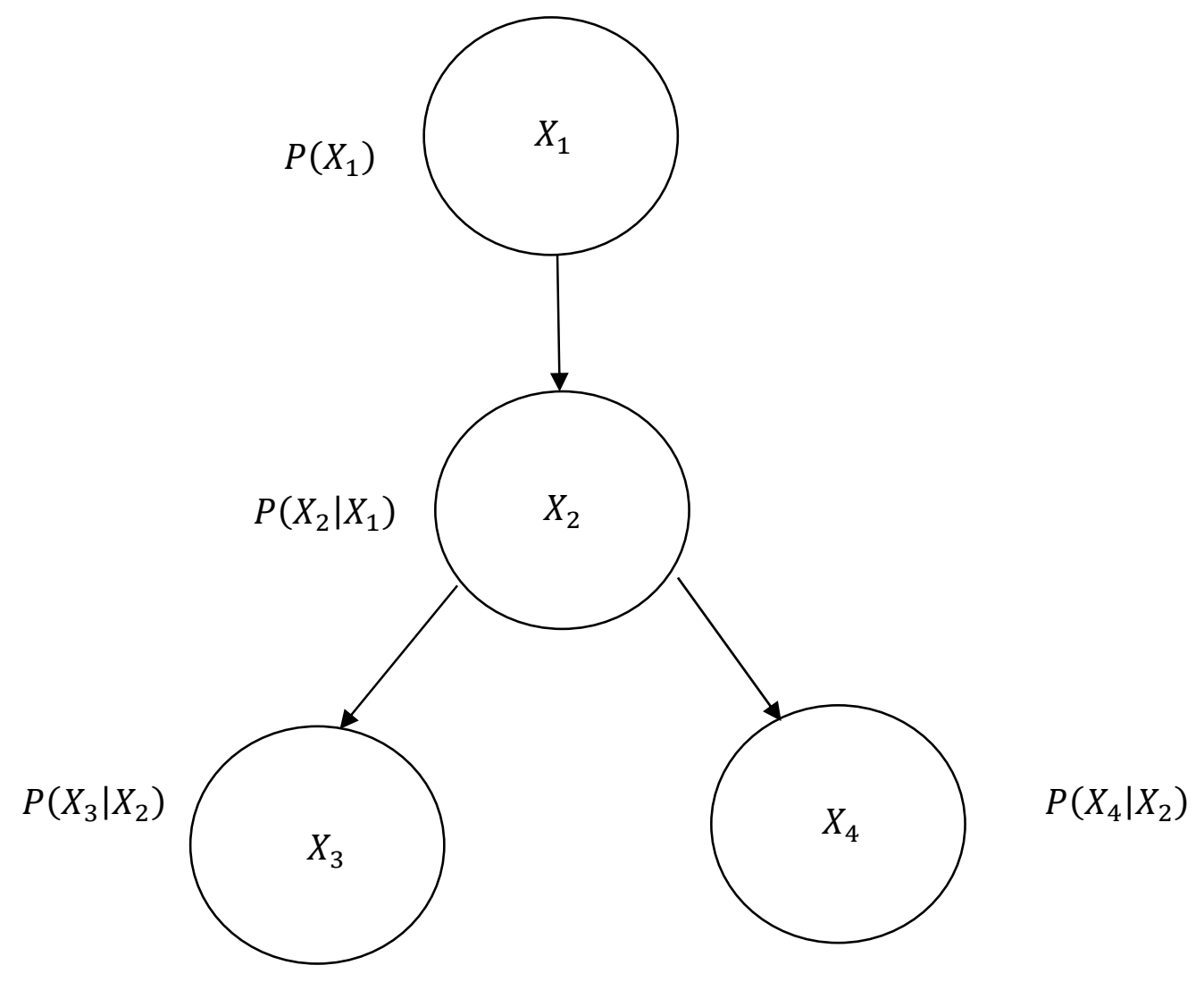

Şekil 1. 4 Değişkenden Oluşan Bayes ağ yapısı

Burada, $P\left(X_{2} \mid X_{1}\right)$ ile $X_{1}$ veildiğinde $X_{2}$ 'nin koşullu olasılığı ifade edilmektedir.

Oluşturulan ağda, $X_{1}$ rasgele değişkeni $X_{2}$ rasgele değişkeninin ebeveyni, $X_{2}$ rasgele değişkeni ise $X_{1}$ rasgele değişkeninin çocuğudur. Aynı şekilde $X_{3}$ ve $X_{4}$ rasgele değişkenleri $X_{2}$ rasgele değişkeninin çocuğudur. $X_{1}$ rasgele değişkeninin ebeveyni olmadığından sadece marjinal olasılığa sahiptir. Bayes Ağları'nda ağda yer alacak değişkenlerin çocuk ya da ebeveyn sayılarına ilişkin herhangi bir kisitlama yoktur. 
Bahsedilen bu şematik ifade Bayes ağlarının birinci bölümüdür ve "niteliksel kısım” olarak ifade edilir. Ağın ikinci bölümü ise "niceliksel kısımdır” ve değişkenlerin sahip olduğu olasılık dağılımlarını gösteren koşullu olasılık tablolarından oluşur.

Ağda yer alan koşullu olasılıkların çarpımı ağın ortak olasılık dağılımını oluşturur. $n$ ağda yer alan değişken sayısını göstermek üzere ortak olasılık dağılımı;

$$
P\left(X_{1}, X_{2}, \ldots, X_{n}\right)=\prod_{i=1}^{n} P\left(X_{i} \mid \operatorname{Ebeveyn}\left(X_{i}\right)\right)
$$

formülü ile ifade edilir (Çinicioğlu ve ark.,2015). Buna göre, Bayes Ağları'nda gözlem geldikçe Bayes teoreminin art arda uygulanması ile ağ yenilenir ve sonsal olasılıklar bulunur. Bayes Ağları ile ağda yer alan tüm değişkenler arasında var olan koşullu olasılık yapısı yansıtılır ve yapılan gözlemler ile ağın dolayısıyla değişkenlerin sonsal olasılıkları yenilenir. Böylelikle, süreçler ve değişkenlerin sahip oldukları olasılıklar yapılan yeni gözlemler ile daha gerçekçi bir şekilde yansıtılır. Bu da Bayes ağlarının mevcut diğer yöntemlere göre bir avantajıdır. Bayes ağlarının bir diğer avantajı ise tek bir çıktı değerine bağlı kalınmaması ve ağda yer alan her değişken için çıkarım yapilabilmesidir.

\section{A $\breve{g}$ yapısının Belirlenmesi}

Bayes ağlarının ağ yapısının belirlenmesinde 2 yaklaşım söz konusudur (Çinicioğlu ve ark.,2015). Birinci yaklaşımda, değişkenler arası bağımlılık ilişkilerinin belirlenmesi ve ilişkilerin yönüne karar verilmesi uzman görüşüne dayanır. Burada ebeveyn ve çocuk düğümleri arasında neden sonuç ilişkisi olduğundan bu yaklaşım "nedensel bayes ağları” olarak adlandırılır (Laskey and Mahoney,1997). İkinci yaklaşımda ise ağ yapısı veri setine bağlı olarak bazı algoritmalar yardımıyla öğrenilir. Öğrenilen ağda ok yönleri nedensellik içermezler, olasılıksal bağımlılık ilişkilerini göstermek için kullanılırlar. Literatürde ağ yapılarının öğrenilmesinde kullanılan bir çok algoritma yer almaktadır (Daly ve ark., 2011). A ̆g yapısının öğrenilmesini sağlayan algoritmalar kullandıkları yönteme göre "kısıt bazlı yöntemler" ve "arama ve skor bazlı yöntemler" olarak ikiye ayrılır. Kısıt bazlı yöntemlerde kullanılan istatistiksel testler aracılığıyla değişkenler arasında koşullu olasılık ilişkilerinin geçerli olup olmadığı araştırılır (Liu ve ark.,2007). Arama ve skor bazlı yöntemlerde ise, veri seti ile oluşturulacak ağ yapısı arasındaki uyum istatistiksel bir skor aracılığıyla belirlenir ve buna göre veri setine en uygun ağ yapısı seçilir. Son zamanlarda bu iki algoritmanın karışımı olan karma algoritmalar da literatürde yer almaktadır. Karma algoritmalar 
hem kısıt bazlı, hem de skor bazlı yöntemleri birleştirerek yapı öğrenme işlemini gerçekleştiren tekniklerdir (Tsamardinos ve ark., 2006). Bu algoritmalarda genel olarak öncelikle bir kısıt bazlı yöntem uygulanır. Öğrenilen bu yapının üzerine bir skor bazlı yöntem uygulanarak son Bayes ağ yapısı meydana getirilir. Karma algoritmalar genel olarak kısıtlama ve maksimize etme şeklinde iki aşamalı olarak uygulanır (Scutari, 2011). Kısıtlama aşamasında düğümlerle ilişkili olan bir düğüm kümesi oluşturulur. Maksimize etme aşamasında sadece düğümle ilişkisi olan çözüm kümesi üzerinden skor bazlı yöntemle Bayes ağı oluşturulur.

Her iki yöntemin kendine göre avantajları ve dezavantajları vardır. Nedensel Bayes ağlarının en büyük avantajı, olasılıksal temellere dayanmasının yanısıra değişkenler arasındaki neden sonuç ilişkisinin de kullanılmasıdır. Böylelikle ağın yorumlanması ve sonuç çıkarım aşamaları daha açıklayıcı olmaktadır. Algoritmalara dayanan Bayes ağlarında ise değişkenler arası ilişkiler sayısal ve istatistiki yöntemlere dayanır. Bu nedenle bu ağların tahmin etme kapasitelerinin daha yüksek olması beklenir (Çinicioğlu ve ark.,2015). Ayrıca değişken sayısı fazla olan araştırmalarda neden sonuç ilişkisi kurmak zorlaşacağından bu yöntemi kullanmak kolaylık sağlayacaktır. Hangi ağ yapısının tercih edileceğini etkileyen önemli faktörlerden biri de ağın uygulanma amacı ve yapılan araştırmanın konusudur.

Bu çalışmada amaç, her iki yöntemle Bayes Ağlarının nasıl oluştuğunu birer örnek üzerinde açıklamaktır.

\subsection{Uzman Görüşüne Dayalı Nedensel Bayes Ă̆ları}

Uzman görüşüne dayalı nedensel Bayes ağları için aşağıdaki senaryo örnek olarak verilebilir (Url-1).

Sabahın erken saatlerinde Bay Body'nin hizmetçisi pencerenin tozunu alırken dışarıda Bay Boddy’nin cansız bedenini görür. Hizmetçi hemen polisi arar ve bir dedektif bu iş için görevlendirilir. Dedektif cesedi inceledikten sonra Bay Boddy'nin başına metal sert bir cisimle vurulduğunu tespit eder. Dedektif evde suça karışmış olması muhtemel hizmetçi ve uşağı sorguya çekerken aynı zamanda suç aleti araştırmasına da girişir ve hizmetçi tarafından kullanılan elektrikli süpürge sapı ile uşak tarafından kullanılan şamdan gözüne çarpar. Dedektif ofísine döndüğünde aşağıdaki notları alır.

Muhtemel suç aletleri;

- Şamdan

- Elektrikli süpürge sap1 
Muhtemel olay vakti;

- Akşam

- Gece yarıs1

Muhtemel katil;

• Hizmetçi

-Uşak

$\checkmark \quad$ Hizmetçi erken kalkıp erken yattığı için gece yarısı cinayet işlemesi olası değildir.

$\checkmark \quad$ Uşak tam bir gece kuşudur.

$\checkmark$ Bir çalışanın diğerinin aletiyle suç işlemesi muhtemel değildir.

$\checkmark$ Hizmetçi vicdan sahibidir ve böyle bir olaya karışsa itiraf edebilir ama uşak için aynı şey geçerli değildir.

Dedektifin tüm bunları değerlendirip oluşturduğu Bayes ağı aşağıdaki gibidir:

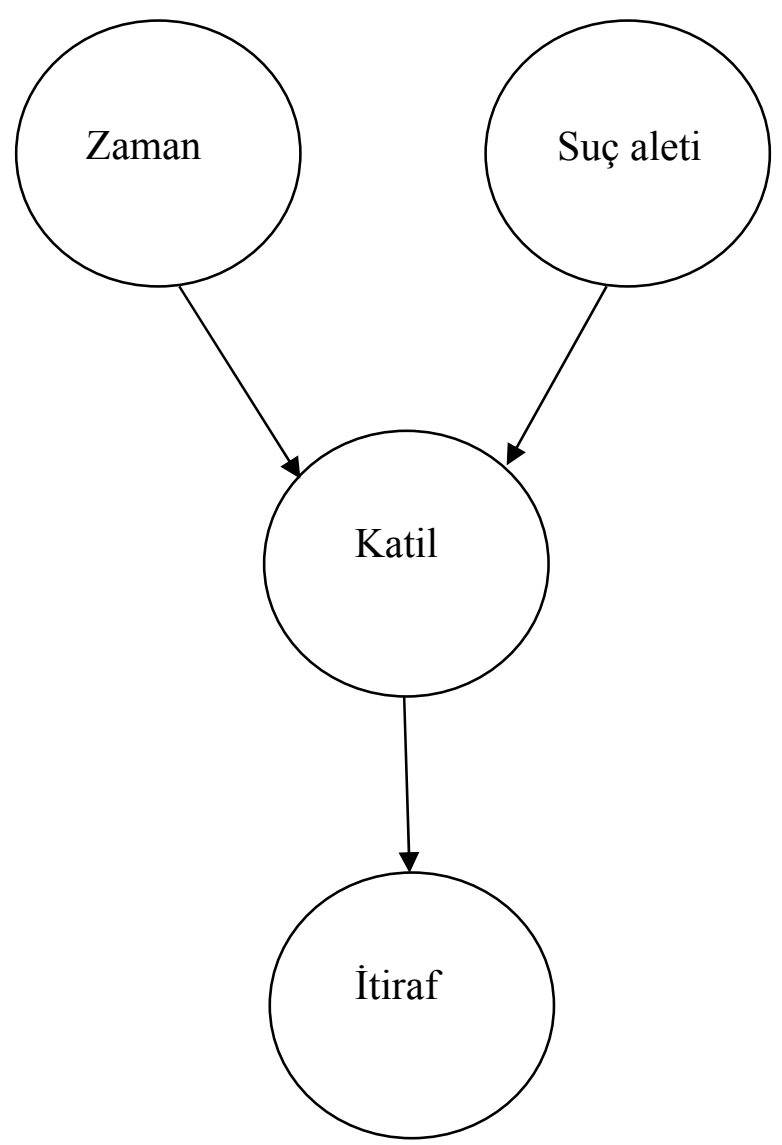

Şekil 2. Uzman görüşüne dayalı Bayes ağ1 
Uzman (dedektif) görüşüne göre kullanılacak önsel ve koşullu olasılıklar aşağıdaki gibidir;

- $P($ Akşam $)=0.05, P($ Gece $)=0.95$

- $P($ Süpürge $)=0.8, P($ Şamdan $)=0.2$

- $P($ Hizmetçi|Akşam, Süpürge $)=0.9$

- $P($ Hizmetçi $\mid$ Akşam, Şamdan $)=0.55$

- $P($ Hizmetçi|Gece, Süpürge $)=0.35$

- $P($ Hizmetçi|Gece, Şamdan $)=0.05$

- $P($ İtiraf $\mid$ Hizmetçi $)=0.95$

- $P\left(\right.$ İtiraf $\left.\mid U_{s ̧ a k}\right)=0.4$

Oluşturulan Bayes ağına göre muhtemel suçlu ve olayın itiraf edilmesi olasılıkları uzman görüşüyle verilen yukarıdaki önsel ve koşullu olasılıklar kullanılarak Bayes teoremi uyarınca aşağıdaki gibi hesaplanır:

Cinayeti hizmetçinin işlemiş olması olasılığı,

$$
\begin{aligned}
& P(\text { Hizmetçi })= P(\text { Hizmetçi } \mid \text { Akşam, Süpürge }) P(\text { Akşam, Süpürge }) \\
&+P(\text { Hizmetçi } \mid \text { Akşam, Şamdan }) P(\text { Akşam, Şamdan }) \\
&+P(\text { Hizmetçi } \mid \text { Gece, Süpürge }) P(\text { Gece, Süpürge }) \\
&+P(\text { Hizmetçi } \mid \text { Gece, Şamdan }) P(\text { Gece, Şamdan }) \\
&= P(\text { Hizmetçi } \mid \text { Akşam, Süpürge }) P(\text { Akşam }) P(\text { Süpürge }) \\
&+ P(\text { Hizmetçi } \mid \text { Akşam,Şamdan }) P(\text { Akşam }) P(\text { Şamdan }) \\
&+ P(\text { Hizmetçi } \mid \text { Gece, Süpürge }) P(\text { Gece }) P(\text { Süpürge }) \\
&+P(\text { Hizmetçi } \mid \text { Gece, Şamdan }) P(\text { Gece }) P(\text { Şamdan }) \\
&=0.9 \times 0.05 \times 0.8+0.55 \times 0.05 \times 0.2+0.35 \times 0.95 \times 0.8+0.05 \times 0.95 \times 0.2 \\
&=0.317 \quad
\end{aligned}
$$

Cinayeti uşağın işlemiş olması olasılığı,

$$
P(U s ̧ a k)=1-P(\text { Hizmetçi })=1-0.317=0.683
$$

Cinayetin itiraf edilmesi olasılı̆̆

$$
P(\text { İtiraf })=P(\text { İtiraf } \mid \text { Hizmetçi }) P(\text { Hizmetçi })+P(\text { İtiraf } \mid U s ̧ a k) P(U s ̧ a k)
$$




$$
=0.95 \times 0.317+0.4 \times 0.683=0.559
$$

olarak bulunur.

$\mathrm{Bu}$ durumda dedektif suçlunun suçunu itiraf edeceğine dair yüksek bir olasılık bulamamıştır. Katilin suçunu itiraf etmesi için hala bir şansının olduğunu düşünerek acele etmeyip bir gün daha bekleme kararı alır.

\subsection{Algoritmalara Dayanan Bayes Ağları}

Çözüme dair tüm mümkün ağların sayısı, değişken sayısı az olan ağlarda bile oldukça büyüktür ve her ağı tek tek denemek oldukça zordur. Bu yüzden mümkün ağlardan en iyilerini seçip değerlendirmek için bazı algoritmalar geliştirilmiştir. Bu algoritmalar yardımıyla ağ oluşturulurken veri ve ön bilgiden yararlanılır.

$\mathrm{Bu}$ algoritmalardan biri de $K 2$ algoritmasıdır. K2 algoritmas1, Cooper ve Herskovits tarafından önerilmiştir. K2 algoritması tıptan eğitim bilimlerine, sosyolojiden mühendisliğe kadar pek çok alanda uygulama olanağına sahiptir. Bunların yanında, literatürde trafik kazaları analiz modeli oluşturulması amacıyla Bayes ağlarından yararlanan pek çok araştırma mevcuttur. Xu ve arkadaşlarının, K2 algoritmasını kullanarak yaptıkları çalışmada algoritmanın kaza faktörlerini açıkça ortaya koyduğu görülmüştür (Xu ve ark., 2011). Olmuş ve Erbaş, Ankara ili ve çevresinde meme kanserine yakalanmış 74 kadın üzerinde bir anket çalışması yapmış ve K2 algoritmasını kullanarak meme kanserinin erken teşhisinin önemini vurgulamış, kansere neden olan etkiler ve bazı önemli sonuçlara yer vermişlerdir (Olmuş ve Erbaş, 2012).

$\mathrm{Bu}$ algoritmada rasgele değişkenlerin sırasıyla birbirleriyle olan olasılıksal ilişkilerine bakılır. Sırasıyla her $X_{i}$ rasgele değişkeni için $X_{i}$ 'den daha küçük numaralı rasgele değişkenlerden ebeveyn kümesi oluşturulur. Hesaplamalar sonucunda olasılık değeri büyük olan küme ebeveyn kümesi olarak seçilir. Her rasgele değişken için algoritma tekrarlanır. Burada,

$\pi_{i}=i$. rasgele değişken için ebeveyn kümesi(başlangıçta boş küme olarak seçilir)

$r_{i}=i$. rasgele değişkenin alacağı tüm mümkün değerlerin sayısı

$D=$ ebeveyn kümesi için seçilen rasgele değişkenin aldığı değerler kümesi

$q_{i}=D$ kümesinin eleman sayısı

$\alpha_{i j k}=i$ ve $j$ rasgele değişkenlerinin $k$ değerini kaç kez aldıklarının sayısı

$N_{i j k}=\alpha_{i j k}$ değerlerinin toplamı 
$z=i$. rasgele değişkenden önce gelen rasgele değişkenlerden oluşturulan ebeveyn kümesi (örneğin 3 düğüme sahip bir veri setinde $X_{3}$ rasgele değişkeni için $\left\{X_{1}\right\},\left\{X_{2}\right\}$ ve $\left\{X_{1}, X_{2}\right\}$ kümeleridir)

$u=$ bir rasgele değişkenin kendisinden önce gelen rasgele değişkenlerden oluşan ebeveyn sayısının maksimumu (örneğin 3. sıradaki rasgele değişken için $u=2$ dir)

olacak biçimde olasıl1k değerleri

$$
f\left(i, \pi_{i}\right)=\prod_{j=1}^{q_{i}} \frac{\left(r_{i}-1\right) !}{\left(N_{i j}+r_{i}-1\right) !} \prod_{k=1}^{r_{i}} \alpha_{i j k} !
$$

ile hesaplanır (Cooper ve Herskovits, 1993). Buna göre K2 algoritmasının adımları aşağıdaki gibi verilir,

A1) $\pi_{i}=\emptyset$ olarak seçilir.

A2) $P_{\text {eski }}=f\left(i, \pi_{i}\right)$ olasılığı hesaplanır.

A3) $\left|\pi_{i}\right|<u$ ise sirasıyla $z \quad$ kümeleri belirlenir. Belirlenen $z \quad$ kümelerinden $f\left(i, \pi_{i} \cup\{z\}\right)$ fonksiyonları hesaplanır. Bu fonksiyonların maksimumu $P_{y e n i}$ olarak seçilir.

A4) Eğer $P_{y e n i}>P_{e s k i}$ ise $P_{e s k i}=P_{y e n i}$ olarak seçilir ve $\pi_{i}=\pi_{i} \cup\{z\}$ olur.

$A 5)$ En büyük olasılık değerini veren z kümesinin elemanı ya da elemanları $X_{i}^{\prime}$ nin ebeveyni olur.

Tüm $i$ değerleri için algoritma işletilir her $i$ değeri için ebeveynler bulunur ve ağ oluşturulur.

K2 algoritması kullanılarak Bayes Ağlarının nasıl oluşturulduğu aşağıdaki örnek üzerinde adım adım anlatılmıştır.

Bir ilköğretim okulunda, drama derslerinin çocukların bedensel, zihinsel, sosyal ve kişisel gelişimine katkısını belirlemek amacıyla bir anket çalışması hazırlanmış ve sınıf öğretmenlerinden öğrencileri için bu soruları cevaplaması istenmiştir.

Durumlar yani rasgele değişkenler, drama dersinin çocuğun çeşitli gelişimsel farklılıklarını gözlemleyecek şekilde oluşturulmuştur. Bu rasgele değişkenler sırasıyla;

$X_{1}$ : İlkokullarda drama dersi çocuğun özgüvenini geliştirir

$X_{2}$ : İlkokullarda drama dersi çocuğun cesaret ve ifade gücünü geliştirir

$X_{3}$ : İlkokullarda drama dersi çocuğun problemlerle baş etme ve çözüm üretme yeteneğini geliştirir 
biçiminde belirlenmiştir.

Her bir soru için evet (1) ya da hayır (0) gibi iki durum söz konusudur ve anket soruları ilkokul öğretmenleri tarafindan bu doğrultuda cevaplanmıştır. Bu şekilde oluşturulan veri seti Tablo 1 de verildiği gibidir. Bu veri seti kullanılarak K2 algoritması ile Bayes ağ1 oluşturulmak istendiğinde izlenecek adımlar aşağıdaki gibidir.

Tablo 1. Veri Seti

\begin{tabular}{cccc}
\hline & $\boldsymbol{X}_{\mathbf{1}}$ & $\boldsymbol{X}_{\mathbf{2}}$ & $\boldsymbol{X}_{\mathbf{3}}$ \\
\hline $\mathbf{1}$ & 0 & 0 & 0 \\
$\mathbf{2}$ & 0 & 0 & 1 \\
$\mathbf{3}$ & 0 & 0 & 1 \\
$\mathbf{4}$ & 0 & 0 & 1 \\
$\mathbf{5}$ & 0 & 1 & 1 \\
$\mathbf{6}$ & 0 & 1 & 1 \\
$\mathbf{7}$ & 1 & 0 & 0 \\
$\mathbf{8}$ & 1 & 0 & 0 \\
$\mathbf{9}$ & 1 & 0 & 0 \\
$\mathbf{1 0}$ & 1 & 1 & 0 \\
$\mathbf{1 1}$ & 1 & 1 & 0 \\
$\mathbf{1 2}$ & 1 & 1 & 1 \\
$\mathbf{1 3}$ & 1 & 1 & 1 \\
$\mathbf{1 4}$ & 1 & 1 & 1 \\
$\mathbf{1 5}$ & 1 & 1 & 1 \\
\hline
\end{tabular}

$\boldsymbol{i}=\mathbf{1}$ durumu için algoritma adımları aşağıdaki gibidir;

A1) $\pi_{1}=\varnothing$

A2) $r_{1}=2\left(X_{1}\right.$ rasgele değişkeni 0 ve 1 olmak üzere 2 değer alır),

Başlangıçta başka bir rasgele değişkenle etkileşim olmadığından $q_{1}$ ve $j$ ihmal edilir,

$$
\begin{aligned}
& \alpha_{1 \_1}=6\left(x_{1}=0 \text { olan göze sayısı }\right) \\
& \alpha_{1 \_2}=9\left(x_{1}=1 \text { olan göze sayıs1 }\right) \\
& N_{1 \_-}=\alpha_{1 \_1}+\alpha_{1 \_2}=15 \text { olmak üzere; } \\
& P_{\text {eski }}=f\left(i, \pi_{i}\right)=f(1, \emptyset) \\
& \quad=\prod_{j=1}^{q_{1}} \frac{\left(r_{1}-1\right) !}{\left(N_{i j}+r_{1}-1\right) !} \prod_{k=1}^{r_{1}} \alpha_{1 j k} !=\frac{\left(r_{1}-1\right) !}{\left(N_{1-}+r_{1}-1\right) !} \prod_{k=1}^{r_{1}} \alpha_{1 \_k} !=\frac{(2-1) !}{(15+2-1) !} 6 ! 9 !=\frac{1}{80080}
\end{aligned}
$$

$\boldsymbol{i}=\mathbf{2}$ durumu için algoritma adımları aşağıdaki gibidir; 
A1) $\pi_{2}=\varnothing$

A2) $r_{2}=2\left(X_{2}\right.$ rasgele değişkeni 0 ve 1 olmak üzere 2 değer alır $)$,

Başlangıçta başka bir rasgele değişkenle etkileşim olmadığından $q_{2}$ ve $j$ ihmal edilir,

$$
\begin{aligned}
& \alpha_{2 \_1}=7\left(x_{2}=0 \text { olan göze sayıs }\right) \\
& \alpha_{2 \_}=8\left(x_{2}=1 \text { olan göze sayıs }\right), \\
& N_{2_{-}}=\alpha_{2 \_1}+\alpha_{2 \_}=15 \text { olmak üzere; } \\
& P_{e s k i}=f\left(i, \pi_{i}\right)=f(2, \emptyset) \\
& =\prod_{j=1}^{q_{2}} \frac{\left(r_{2}-1\right) !}{\left(N_{i j}+r_{2}-1\right) !} \prod_{k=1}^{r_{2}} \alpha_{2 j k} !=\frac{\left(r_{2}-1\right) !}{\left(N_{2-}+r_{2}-1\right) !} \prod_{k=1}^{r_{2}} \alpha_{2 \_} !=\frac{(2-1) !}{(15+2-1) !} 7 ! 8 !=\frac{1}{102960}
\end{aligned}
$$

A3) Ebeveyn $\left(X_{2}\right)=\left\{X_{1}\right\}$ olarak seçilir yani $z=\left\{X_{1}\right\}$ dir.

$$
\begin{aligned}
& \pi_{2}=\emptyset \cup\left\{X_{1}\right\} \\
& D=\left(\left(x_{1}=0\right),\left(x_{1}=1\right)\right) \\
& q_{2}=2 \\
& \alpha_{211}=4\left(x_{1}=0, x_{2}=0 \text { olan göze sayısı }\right) \\
& \alpha_{212}=2\left(x_{1}=0, x_{2}=1 \text { olan göze sayısı }\right) \\
& \alpha_{221}=3\left(x_{1}=1, x_{2}=0 \text { olan göze sayısı }\right) \\
& \alpha_{222}=6\left(x_{1}=1, x_{2}=1\right. \text { olan göze sayıs } \\
& N_{21}=\alpha_{211}+\alpha_{212}=6 \\
& N_{22}=\alpha_{221}+\alpha_{222}=9 \text { olmak üzere; } \\
& P_{y e n i}=f\left(i, \pi_{i}\right)=f\left(2, \emptyset \cup\left\{X_{1}\right\}\right) \\
& =\prod_{j=1}^{q_{2}} \frac{\left(r_{2}-1\right) !}{\left(N_{i j}+r_{2}-1\right) !} \prod_{k=1}^{r_{2}} \alpha_{2 j k} ! \\
& \quad=\frac{\left(r_{2}-1\right) !}{\left(N_{21}+r_{2}-1\right) !} \prod_{k=1}^{2} \alpha_{21 k} ! \frac{\left(r_{2}-1\right) !}{\left(N_{22}+r_{2}-1\right) !} \prod_{k=1}^{2} \alpha_{22 k} ! \\
& =\frac{(2-1) !}{(6+2-1) !} 4 ! 2 ! \frac{(2-1) !}{(9+2-1) !} 3 ! 6 !=\frac{1}{88200}
\end{aligned}
$$

$P_{e s k i}=\frac{1}{102960}<P_{y e n i}=\frac{1}{88200}$ olduğundan $X_{2}$ rasgele değişkeninin ebeveyni $X_{1}{ }^{\prime}$ dir. 
$\mathbf{i}=\mathbf{3}$ durumu için algoritma adımları aşağıdaki gibidir;

A1) $\pi_{3}=\emptyset$

A2) $r_{3}=2\left(X_{3}\right.$ rasgele değişkeni 0 ve 1 olmak üzere 2 değer alır),

Başlangıçta başka bir rasgele değişkenle etkileşim olmadığından $q_{3}$ ve $j$ ihmal edilir,

$$
\begin{aligned}
& \alpha_{3_{\_} 1}=6\left(x_{2}=0 \text { olan göze sayısı }\right) \\
& \alpha_{3 \_2}=9\left(x_{2}=1 \text { olan göze say1sı }\right) \\
& N_{3_{-}}=\alpha_{3_{-} 1}+\alpha_{3 \_2}=15 \text { olmak üzere; } \\
& P_{e s k i}=f\left(i, \pi_{i}\right)=f(3, \emptyset) \\
& =\prod_{j=1}^{q_{3}} \frac{\left(r_{3}-1\right) !}{\left(N_{i j}+r_{3}-1\right) !} \prod_{k=1}^{r_{3}} \alpha_{3 j k} !=\frac{\left(r_{3}-1\right) !}{\left(N_{3-}+r_{3}-1\right) !} \prod_{k=1}^{r_{3}} \alpha_{3_{k}} ! \\
& =\frac{(2-1) !}{(15+2-1) !} 6 ! 9 !=\frac{1}{80080}
\end{aligned}
$$

A3) Ebeveyn $\left(X_{3}\right)$ sirasiyla $z=\left\{X_{1}\right\}, z=\left\{X_{2}\right\}$ ve $z=\left\{X_{1}, X_{2}\right\}$ olarak seçilir,

$$
\begin{aligned}
& z=\left\{X_{1}\right\} \text { durumu için } \\
& \pi_{3}=\emptyset \cup\left\{X_{1}\right\} \\
& D=\left(\left(x_{1}=0\right),\left(x_{1}=1\right)\right) \\
& q_{3}=2 \\
& \alpha_{311}=1\left(x_{1}=0, x_{2}=0 \text { olan göze sayıs1 }\right) \\
& \alpha_{312}=5\left(x_{1}=0, x_{2}=1 \text { olan göze sayıs1 }\right) \\
& \alpha_{321}=5\left(x_{1}=1, x_{2}=0 \text { olan göze sayıs1 }\right) \\
& \alpha_{322}=4\left(x_{1}=1, x_{2}=1 \text { olan göze sayıs1 }\right) \\
& N_{31}=\alpha_{311}+\alpha_{312}=6 \\
& N_{32}=\alpha_{321}+\alpha_{322}=9 \text { olmak üzere; } \\
& P_{y e n i}=f\left(i, \pi_{i}\right)=f\left(3, \emptyset \cup\left\{X_{1}\right\}\right) \\
& =\prod_{j} \frac{\left(r_{3}-1\right) !}{\left(N_{i j}+r_{3}-1\right) !} \prod_{k=1}^{r_{3}} \alpha_{3 j k} ! \\
& =\frac{\left(r_{3}-1\right) !}{\left(N_{31}+r_{3}-1\right) !} \prod_{k=1}^{2} \alpha_{31 k} ! \frac{\left(r_{3}-1\right) !}{\left(N_{32}+r_{3}-1\right) !} \prod_{k=1}^{2} \alpha_{32 k} !
\end{aligned}
$$




$$
=\frac{(2-1) !}{(6+2-1) !} 1 ! 5 ! \frac{(2-1) !}{(9+2-1) !} 5 ! 4 !=\frac{1}{52920}
$$

$z=\left\{X_{2}\right\}$ durumu için

$$
\begin{aligned}
& \pi_{3}=\emptyset \cup\left\{X_{2}\right\} \\
& D=\left(\left(x_{2}=0\right),\left(x_{2}=1\right)\right) \\
& q_{3}=2 \\
& \alpha_{311}=4\left(x_{1}=0, x_{2}=0 \text { olan göze sayısı }\right) \\
& \alpha_{312}=3\left(x_{1}=0, x_{2}=1\right. \text { olan göze sayısı) } \\
& \alpha_{321}=2\left(x_{1}=1, x_{2}=0\right. \text { olan göze sayısı) } \\
& \alpha_{322}=6\left(x_{1}=1, x_{2}=1 \text { olan göze sayıs1 }\right) \\
& N_{31}=\alpha_{311}+\alpha_{312}=7 \\
& N_{32}=\alpha_{321}+\alpha_{322}=8 \text { olmak üzere; }
\end{aligned}
$$

$$
\begin{aligned}
& P_{\text {yeni }}=f\left(i, \pi_{i}\right)=f\left(3, \emptyset \cup\left\{X_{2}\right\}\right) \\
& =\prod_{j=1}^{q_{3}} \frac{\left(r_{3}-1\right) !}{\left(N_{i j}+r_{3}-1\right) !} \prod_{k=1}^{r_{3}} \alpha_{3 j k} ! \\
& \quad=\frac{\left(r_{3}-1\right) !}{\left(N_{31}+r_{3}-1\right) !} \prod_{k=1}^{2} \alpha_{31 k} ! \frac{\left(r_{3}-1\right) !}{\left(N_{32}+r_{3}-1\right) !} \prod_{k=1}^{2} \alpha_{32 k} ! \\
& \quad=\frac{(2-1) !}{(7+2-1) !} 4 ! 3 ! \frac{(2-1) !}{(8+2-1) !} 2 ! 6 !=\frac{1}{70560}
\end{aligned}
$$

$z=\left\{X_{1}, X_{2}\right\}$ durumu için

$$
\pi_{3}=\emptyset \cup\left\{X_{1}, X_{2}\right\}
$$$$
D=\left(\left(x_{1}=0, x_{2}=0\right),\left(x_{1}=0, x_{2}=1\right),\left(x_{1}=1, x_{2}=0\right),\left(x_{1}=1, x_{2}=1\right)\right)
$$$$
q_{3}=4
$$$$
\alpha_{311}=1\left(x_{1}=0, x_{2}=0, x_{3}=0 \text { olan göze say1s1 }\right)
$$$$
\alpha_{312}=3\left(x_{1}=0, x_{2}=0, x_{3}=1\right. \text { olan göze sayısı) }
$$$$
\alpha_{321}=0\left(x_{1}=0, x_{2}=1, x_{3}=0 \text { olan göze sayısı }\right)
$$$$
\alpha_{322}=2\left(x_{1}=0, x_{2}=1, x_{3}=1\right. \text { olan göze sayıs1) }
$$$$
\alpha_{331}=3\left(x_{1}=1, x_{2}=0, x_{3}=0\right. \text { olan göze sayısı) }
$$$$
\alpha_{332}=0\left(x_{1}=1, x_{2}=0, x_{3}=1\right. \text { olan göze say1s1) }
$$$$
\alpha_{341}=2\left(x_{1}=1, x_{2}=1, x_{3}=0 \text { olan göze sayıs1 }\right)
$$ 


$$
\begin{aligned}
& \alpha_{342}=4\left(x_{1}=1, x_{2}=1, x_{3}=1 \text { olan göze sayıs1 }\right) \\
& N_{31}=\alpha_{311}+\alpha_{312}=4 \\
& N_{32}=\alpha_{321}+\alpha_{322}=2 \text { olmak üzere; } \\
& N_{33}=\alpha_{331}+\alpha_{332}=3 \\
& N_{34}=\alpha_{341}+\alpha_{342}=6 \text { olmak üzere; } \\
& P_{y e n i}=f\left(i, \pi_{i}\right)=f\left(3, \varnothing \cup\left\{X_{1}, X_{2}\right\}\right) \\
& =\prod_{j=1}^{q_{3}} \frac{\left(r_{3}-1\right) !}{\left(N_{i j}+r_{3}-1\right) !} \prod_{k=1}^{r_{3}} \alpha_{3 j k} \text { ! } \\
& =\frac{\left(r_{3}-1\right) !}{\left(N_{31}+r_{3}-1\right) !} \prod_{k=1}^{2} \alpha_{31 k} ! \frac{\left(r_{3}-1\right) !}{\left(N_{32}+r_{3}-1\right) !} \prod_{k=1}^{2} \alpha_{32 k} \text { ! } \\
& \times \frac{\left(r_{3}-1\right) !}{\left(N_{33}+r_{3}-1\right) !} \prod_{k=1}^{2} \alpha_{33 k} ! \frac{\left(r_{3}-1\right) !}{\left(N_{34}+r_{3}-1\right) !} \prod_{k=1}^{2} \alpha_{34 k} ! \\
& =\frac{(2-1) !}{(4+2-1) !} 1 ! 3 ! \frac{(2-1) !}{(2+2-1) !} 0 ! 2 ! \frac{(2-1) !}{(3+2-1) !} 3 ! 0 ! \frac{(2-1) !}{(6+2-1) !} 2 ! 4 ! \\
& =\frac{1}{25200} \\
& f(3, \varnothing)=\frac{1}{80080}<f\left(3, \varnothing \cup\left\{X_{2}\right\}\right)=\frac{1}{70560}<f\left(3, \emptyset \cup\left\{X_{1}\right\}\right)=\frac{1}{52920} \\
& <f\left(3, \varnothing \cup\left\{X_{1}, X_{2}\right\}\right)=\frac{1}{25200}
\end{aligned}
$$

olduğundan $X_{3}$ rasgele değişkeninin ebeveyni $X_{1}$ ve $X_{2}$ rasgele değişkenleridir.

Hesaplamalar sonucu ortaya çıkan Bayes ağı grafiksel olarak Şekil 3 deki gibi gösterilebilir.

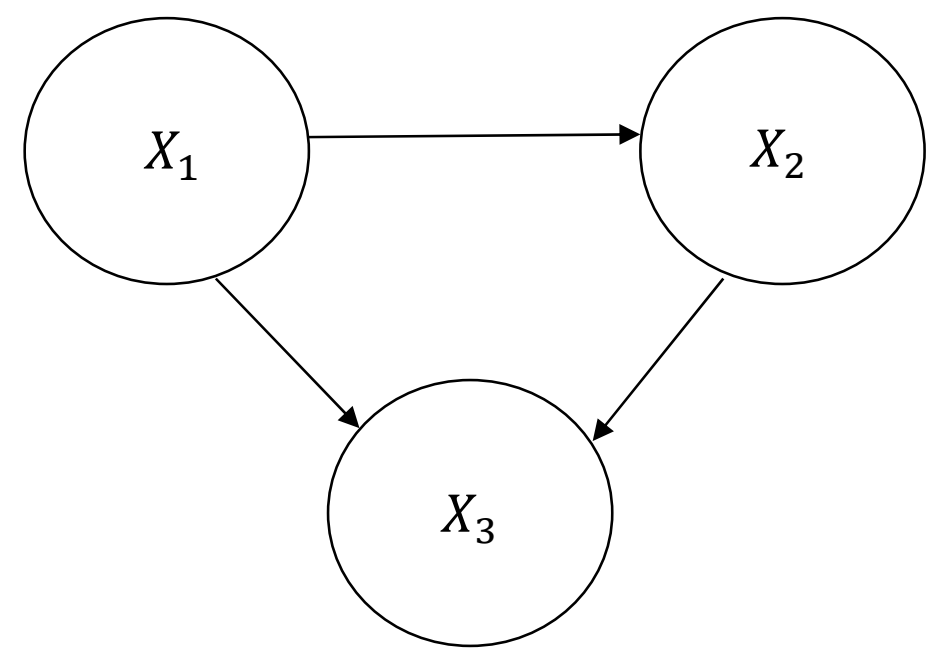

Şekil 3. K2 algoritması ile oluşturulan Bayes ağ1 
Hesaplamalar sonucu ortaya çıkan Bayes ağına göre $X 1, X 2$ 'nin ebeveyni; $X 1$ ve $X 2, X 3$ 'ün ebeveynidir.

Buradan yola çıkarak drama dersinin çocuğun gelişimi üzerinde neden-sonuç ilişkisi içerisinde olan durumlarını açıkça ifade etmek mümkündür.

$\checkmark \quad$ Drama derslerinin çocuğun özgüven gelişimine katkısı, cesaret ve ifade gücü gelişimi ile problemlerle baş etme ve problemlere çözüm üretme gelişimleri arasında bir neden sonuç ilişkisi vardir.

$\checkmark \quad$ Özgüveni gelişen çocuk kendini daha iyi ifade edecek ve problemlerle daha kolay başedebilecektir.

Aynı şekilde cesareti ve kendini ifade gücü gelişen çocuğun problemlere çözüm üretme yeteneği de gelişecektir.

$\checkmark \quad$ Oluşturulan bayes ağı sayesinde bu ilişkiler kolaylıkla ve sistemli bir biçimde görülmektedir.

Öğretmenlere drama dersinin çeşitli gelişimsel alanlardaki neden sonuç ilişkisi ve bunların hangi olasılıklarla oluştuğunu açık bir biçimde vermesi yönüyle yukarıdaki Bayes ağı konuyla ilgili çıkarım ve yorumlamalarda hem görsel hem de istatistiksel açıdan büyük kolaylık sağlamaktadır.

Görüldüğü gibi sadece 3 değişken olduğunda bile K2 algoritmasını kullanarak Bayes ağını oluşturmak için yapılması gereken matematiksel işlem oldukça fazladır. Bu nedenle bu işlemleri yapacak çok sayıda bilgisayar programı geliştirilmiştir (Netica, Hugin,...). Geliştirilen bu bilgisayar programları yardımıyla değişken sayısının çok olduğu durumlarda bile ağ yapısı kolaylıkla elde edilebilmekte ve sonuçlar yorumlanabilmektedir.

Bu çalışmada sadece elle çözüm göz önüne alınmış, konuya merakı olan araştırmacılara konuyla ilgili temel bilgilerin verilmesi hedeflenmiştir. Uygulamalarda karşılaşılacak problemlerin çözümünde veriden ağ yapısını öğrenme işlemleri için geliştirilen bilgisayar programlarının kullanılması önerilmektedir.

\section{Sonuç}

Bayes ağları ile değişkenler arasındaki ilişkiler oklar ve düğümler yardımıyla grafiksel olarak gösterilirler. Okların yönüne göre isimlendirilen ebeveyn ve çocuk rasgele değişkenleri ile bu rasgele değişkenlere ait koşullu ve marjinal olasılıklar istenilen bir olayın olasılığının hesaplanmasında kullanılırlar. 
Bayes ağları "Nedensel Bayes Ağları” ve "Algoritmalara Dayalı Bayes Ağları” olmak üzere iki yöntemle oluşturulabilir. Her iki yöntemin kendi içerisinde avantajları mevcuttur ve araştırma konusuna göre bunlardan uygun olanı tercih edilmelidir.

Ağ oluşturulurken kullanılan algoritmalardan biri K2 algoritmasıdır. Bu çalışmada verilen bir örnek üzerinden K2 algoritmasının adım adım işleyiş̧i anlatılıı̧ ve verilere ait Bayes ağı oluşturulmuştur.

\section{Kaynaklar}

Cooper,G. F., Herskovits, E., (1993). A bayesian method for the induction of probabilistic networks from data. Technical Report KSL-91-02, Knowledge Systems Laboratory. Medical Computer Science. Stanford University School of Medicine, Stanford, CA 94305-5479, Updated Nov. Available at: http://smiweb.stanford.edu/pubs/SMI Abstracts/SMI-91-0355.html.

Çinicioğlu, E. N., Ekici, Ş. Ö., Ülengin, F., (2015). Bayes Ağ Yapısının Oluşturulmasında Farklı Yaklaşımlar: Nedensel Bayes Ağları ve Veriden Ağ Öğrenme. Halil Sarıaslan Armağan Kitap, Ali Argun Karacabeyi Ed. Siyasal Kitabevi-Ünal Sevindik, Ankara, ss. 267-286.

Daly, R., Shen, Q., Aitken, S., (2011). Learning Bayesian networks: approaches and issues, The Knowledge Engineering Review, Vol. 26:2, 99-157.

Laskey, K. B., Mahoney, S. M., (1997). Network fraggments: Representing Knowledge for Constructing Probabilistic Models, Proceedings of the Thirteenth Conference on Uncertainty in Artificial Intelligence, pp. 334-341, Morgan Kaufmann Publishers Inc.

Liu,F., Tian,F., Zhu, Q., (2007). An Improved Greedy Bayesian Network Learning Algorithm on Limited Data. Artificial Neural Networks-ICANN Porto 2007 17th International Conference Proceedings, Lecture Notes in Computer Science, 4668, 49-57.

Olmuş, H., Erbaş, S. O. (2012). Bayes Ağlarda Kümeleme Metotunu Kullanarak Meme Kanseri Tanısının Modellenmesi, Turkiye Klinikleri J Biostat, 4(1):10-19.

Pearl, J., (1988). Probabilistic Reasoning in Inteligent Systems: Networks of Plausible Inference, Morgan Kaufmann.

Scutari M., (2011). Measures of Variability for Graphical Models. PhD thesis, Universita degli Studi di Padova, Dipartimento di Scienze Statistiche.

Tsamardinos I., Aliferis C. F., Statnikov A., (2003). Algorithms for Large Scale Markov Blanket Discovery. In Proceedings of the 16th International Florida Artificial Intelligence Research Society Conference, 376-381.

URL-1. https://www.youtube.com/watch?v=4fcqyzVJwHM (Erişim Tarihi:4 Nisan 2017)

Xu Z. X., Jiang Y., Lin F., Dai L., (2011). The Analysis and Prevent in Traffic Accidents Based on Bayesian Network, Advanced Engineering Forum, Vol.1, pp. 21-25. 